\title{
Evaluating the Relation of Maxillary Posterior Roots to the Floor of Maxillary Sinus in Southern Iraqi Patients, a CBCT Study
}

Aqeel Al-Saedi ( $\sim$ Aqeel.lazim@uobasrah.edu.iq)

University of Basrah

Riad Al-Taee

University of Basrah

Bahaa Al-Bakhakh

University of Basrah

\section{Research Article}

Keywords: Cone beam computed tomography, maxillary sinus, maxillary sinus floor, maxillary molars, maxillary premolars

Posted Date: May 20th, 2021

DOl: https://doi.org/10.21203/rs.3.rs-503766/v1

License: (a) (i) This work is licensed under a Creative Commons Attribution 4.0 International License. Read Full License 


\section{Abstract}

Background: This present study aims to evaluate the type of relationship between roots of maxillary posterior teeth and maxillary sinus.

Methods: Cone beam computed tomography images for 148 patients were evaluated ( 62 males Vs 86 females). A total of 1052 teeth were examined (518 maxillary premolars and 534 maxillary molars). The relation between roots tips and maxillary sinus floor were classified into four types: type 0 , type 1 , type 2 and type 3 , vertical linear distance was measured and distribution of type of relationship in different age groups were evaluated.

Results: Most of single rooted maxillary premolars showed (type 0 ) relationship with maxillary sinus floor (98.1\%) for maxillary first premolars and $(69.5 \%)$ for maxillary second premolars. In buccal roots of double rooted maxillary first premolars, (type 0 ) represented (98.7\%). While for maxillary second premolars occurred in (50\%). Type 0 still the most common appearing type in palatal roots of maxillary first premolars $(92 \%)$ and in maxillary second premolars it appeared in (45.8\%).

In maxillary first molars, (type 0 ) was the most common type which appeared in $43.3 \%, 39.8 \%$ and $38.6 \%$ for mesiobuccal, distobuccal and palatal roots respectively.

The most common appearing type in single rooted and double rooted maxillary second molars, (type 0 ) appeared in (50\%). In mesiobuccal and distobuccal roots (type 1) appeared in $48.1 \%$ and $45.5 \%$, respectively (most common), whereas (type 0 ) was seen most frequently in palatal roots $(39.7 \%)$. There was increased appearance of (type 0 ) in older age group (>45) in maxillary molars roots with statistically significant difference $(P$-value $<0.001)$.

Conclusions: Most of maxillary premolars, maxillary first molars and palatal roots of maxillary second molars were separated from maxillary sinus floor (type 0 ). Most of the mesiobuccal and distobaccal roots of maxillary second molars were in contact with the sinus floor (type1).

\section{Introduction}

The maxillary sinus (MS) is the largest air sinus which is located in the body of the maxilla. It varies in shape, size and position in different individuals and also in different sides of the same individual. The dimensions of the MS can also be different according to the gender and ethnicity. The inferior wall of the MS is curved and extended between the adjacent roots in about half of the population. ${ }^{1}$

The size of MS varies between patients with the floor of the sinus extending between adjacent teeth or between individual roots in about $50 \%$ percent of the population. ${ }^{2}$

Dentists who conduct clinical procedures in the area of posterior maxilla should be aware to the amount of protrusion of teeth roots into the floor of the sinus. The percentage of teeth approaching or penetrating into the sinus varies to a large extent according to the examined sample and the community where these studies were performed ${ }^{3}$. 
The root tips of the maxillary molars (MM) in general are closer to the sinus floor than those of the premolars. An inverse relationship is found between the thickness of bone buccolingually and that of the bone lying superior to the apices of the teeth. ${ }^{4}$

Conventional radiographic techniques have been used in the study of the relationship between maxillary posterior teeth and maxillary sinus floor (MSF). Most of these techniques have limitations that may affect this analysis. The limitation results from the fact that two-dimensional images prevents the correct interpretation of the periapical relation of roots apices to the MSF. The clinical introduction of cone beam computed tomography (CBCT) for use in the diagnosis and planning has contributed to improve treatment approaches .5

Studies that used computed tomography(CT) scan have shown to be even more accurate than cadaveric studies $^{1}$.

When compared with medical CT, CBCT has lower radiation, higher resolution in shorter scanning time. CBCT can produce high-resolution 3D images of oral and maxillofacial region and help to evaluate the relationship between apices of the maxillary roots and MS clearly. ${ }^{6}$

When the roots projects laterally or medially over the sinus, using panoramic images will lead to misinterpretation, and the root will appear to be in the sinus so ordering a CBCT should be considered for assessment of risk associated with oral surgery in maxillary posterior teeth area$^{7}$.

Most abnormalities of the MS were found to be associated with at least one of the maxillary posterior tooth with a periapical lesion. ${ }^{8}$

Sinusitis may result from the spread of either a periapical or periodontal infection to the MS or from iatrogenic perforation of the sinus ${ }^{9}$

Therefore, the assessment of the relationship between roots of posterior teeth and maxillary sinus floor( MSF) is crucial before planning of any dental treatment procedure in posterior maxilla to avoid procedural complications. ${ }^{10}$

Few studies have evaluated relationship between maxillary posterior teeth and MS in Iraqi population ${ }^{8}$ [11-12] with no study made for southern Iraqi patients, so the present study aims to analyze the vertical relationship and vertical linear measurements(VLM) between roots tips of maxillary posterior teeth and MS in a sample of population from Basrah city in south of Iraq.

\section{Materials And Methods}

\subsection{Patients}

This study was approved by Ethical Review Committee at College of Dentistry, university of Basrah. All methods were carried out in accordance with relevant guidelines and regulations. CBCT images for 148 patients (62 males Vs 86 females) were evaluated, these images have been requested for many clinical 
purposes including oral surgery, orthodontics, endodontics and implants in the time period from 15/6/2018 to $1 / 2 / 2020$. The sample of population had an age range between 18-63 years (average age 32.1 years). This study was approved by Ethical Review Committee at College of Dentistry, university of Basrah. All methods were carried out in accordance with relevant guidelines and regulations. 1052 teeth were examined in this study including 518 maxillary premolars (262 maxillary first premolar (MFP) Vs 256 maxillary second premolar (MSP)) and 534 maxillary molars (254 maxillary first molar (MFM) Vs 280 maxillary second molar $(\mathrm{MSM}))$.

The exclusion criteria were as follow: history of trauma/orthodontic treatment to the maxillary arch, pathology affecting size, shape and/or appearance of MS, history of surgical procedures in posterior maxilla, presence of radiographic sign/signs of periapical pathology around one or more of the apices of the included teeth, maxillary posterior teeth with developmental anomalies that could interfere with interpretation of CBCT image, presence of root canal filling, root resorption, fracture or open apex in any of the included teeth and images with artifacts related to technique that affect interpretation.

\subsection{Radiographic technique}

The CBCT images were obtained using a Gendex (GXDP -7000) CBCT machine (Germany) operating at $90 \mathrm{kV}$ and $10 \mathrm{~mA}$, and the scan time was 13 seconds. The image dimension used was $400.400 .300 \mathrm{IJK}$, image size (field of view) was $80.0 * 80.0 * 60.0 \mathrm{~mm}$, while image resolution was $0.20 * 0.20 * 0.20 \mathrm{~mm}$. The minimum slice thickness was $0.5 \mathrm{~mm}$ with slice interval $1 \mathrm{~mm}$. The detector resolution was $200 \mu \mathrm{m}$. Scan's procedures were done according to the manufacturer's instructions protocol. All CBCT examinations were carried out by an oral radiologist with more than 12 years' experience with obligation to ALARA principle.

\subsection{Evaluation of the images}

The CBCT images were analyzed using an inbuilt software (GxPicture ${ }^{T M}$ ) (Invivo5 dental viewer application, version 2.0.1) running in a 64-bit Windows 10 system. All the images were analyzed using Lenovo LCD screen (17 inch) with a resolution of $(1920 \times 1080)$ pixels in a dark room. Contrast and brightness of images was adjusted during examination using the software's image processing tools to get the optimal visualization condition. To determine the exact positions of roots apices and floor of maxillary antrum, the examiners were scrolling through the axial, coronal and sagittal views. The CBCT images were evaluated by a professional oral radiologist, a maxillofacial surgeon and an endodontist separately. The obtained data were compared, and the incompatible data were rechecked and reassessed by the examiners at the same time to obtain consensus in their radiographic findings. A second reading was done after one month using approximately $20 \%$ of the images selected randomly to assess intraobserver reliability.

The included teeth were evaluated on axial, coronal and sagittal sections for the relation between roots apices and MSF, decision was reported according to coronal section, this relation was classified according to Jung and Cho classification ${ }^{13}$ into four types as shown in figure 1 :

Linear measurements for the vertical distance between the roots' apices and the inferior wall of MS was obtained using linear measurement tool built in (Invivo5 dental viewer) software as seen on coronal and sagittal sections, when the measured distance was different between the two planes (coronal and sagittal), 
the shortest value was depended. The measurement was defined positive when the root apex lies away from or below the inferior wall of MS (fig.3 a), while measurement was defined negative when root apex protruded into or above the inferior wall of MS (fig.3 b).

\subsection{Statistical analysis:}

Statistics were recorded for the type of relation between maxillary posterior roots apices and inferior wall of maxillary sinus on both sides of maxilla, patient's gender and age. The sinus relation types among different age groups were assessed using Chi-squared t test. Intra-observer reliability was analyzed with Cohen's Kappa tests. The SPSS for Windows software (ver. 22.0) was used to conduct the statistical analysis tests.

\section{Results}

The kappa values for the intra-examiner agreements of each examiner were 0.91, while for inter-examiner agreement, the kappa values were 0.821 and 0.852 for the first and second assessments, respectively. There was a good intra-examiner and inter-examiner agreement.

As seen in table1 and figure 4, the vast majority of MFP roots in case of single rooted teeth, their apices were classified to have (type 0 ) relationship with MSF (98.1\%). While for MSP, type 0 still representing the most appearing type but in slightly less ratio (69.5\%). In case of buccal roots of double rooted MFP, (type 0 ) represented (98.7\%). While for MSP, type 0 accounted for only (50\%). Type 0 still the most common appearing type in palatal roots of MFP (92\%) and MSP with a ratio of (45.8\%).

Table 2 shows that for single rooted MSM, the most common appearing type of relationship was type 1 that appeared in $45.6 \%$ of the cases. For MBR in multirooted MM, type 0 was the most commonly seen type in MFM (41.4\%) while for MSM type 1 was the dominant type (45.5\%). In DBR, type 0 was also the most common type in MFM (39.8\%), while type 1 was seen more in MSM (48.1\%).

For PR, type 0 was the most common type in both first and second molars (38.3\% Vs $37.9 \%$ ) (figure 5).

In table 3 it was noticed that in double rooted MSM, type 0 and type 1 only occurred with equal distribution $(50 \%$ Vs $50 \%)$.

Table 4 showed that type 0 is also the most common appearing type in almost all age groups in maxillary first and second premolars.

In table 5 we can notice that type 0 is appearing in a larger ratio in older age group (>45 years) in MFM and also in MSM but in a lesser extent.

Table 6 showed that the longest VLM between MP roots and MSF is indicated for MFP $(0-18.96 \mathrm{~mm})$, while MSP was closest to MSF (-3.65-12.77 mm).

It can be noticed in table 7 that MBR of MSM have the shortest distance to the MSF while MBR of MFM and PR of MSM have the longest distance to the sinus floor. 
In double rooted MSM, BR were closest to the MSF than PR. Table (8).

\section{Discussion}

The apices of the maxillary posterior teeth lie in close proximity to, or within, the sinus. So, both surgical and nonsurgical endodontic procedures in this area could lead to perforation of the inferior recess of a MS [4].

It is so important to evaluate the relationship between the roots of maxillary posterior teeth and MSF when planning any dental or surgical procedure to avoid related procedural complication [14].

Using CBCT could improve accuracy in diagnosing protruding roots into the sinus as was reported by RoqueTorres et al. who have found that out of 819 roots seen to be protruded into the sinus on panoramic radiography, only 80 of them had the same position on CBCT [15], similar finding was reported by Shakhwan et al. when comparing panoramic radiography to medical CT [11].

The relationship between the root apices and the MSF could be interpreted differently between coronal and sagittal planes on CBCT, so a root may be seen to be protruded inside the sinus on one plane, but it is seen either in contact with or away from the sinus, so a root will be only be classified to be protruded into the sinus when it shows protrusion in all planes of CBCT images [16]. However, even though a root could be seen to be protruded into the sinus in only one plane, it should be classified as high-risk factor for evoking odontogenic sinus infection and/or sinus floor perforation during surgical procedures. Similarly, the mean distance between the root apex and the MSF was not similar when measured on coronal and sagittal planes. So, the distance between the root apex and the MSF should be measured on both coronal and sagittal CBCT planes and the shortest value would be selected as the final measurement [16-17]. This fact was depended when making VLM in the present study.

In the present study, most of the MP roots were observed to be separated from the floor of MS (type 0) as seen in (table 1), such result was similar to was stated by many researchers [4]' [18]' [14]' [19]. Appearance of (type 0) was reported to occur more commonly in MFP (98.1\%) than in MSP $(70.4 \%)$, such finding supports what was reported by most of the previous studies [5]' [20-22].

In our present study, MM were reported to be more approximate to the MSF with the shorter vertical distance was recorded for the MBR of MSM (table 2). In single rooted MSM we found that (type1) occurs in more ratio than other types (45.6\%), while for MBR of multirooted MM; (type 0) appeared more commonly in MFM (41.4\%) meanwhile (type1) was the most common type in case of MSM (45.5\%). The same finding was reported for DBR where (type 0) accounts for 39.8\% in MFM and (type 1) accounts for 49.1\% in MSM. For PR, (type 0 ) appeared more commonly in both molars, where it appeared in $38.3 \%$ and $37.9 \%$ in MFM and MSM respectively, this finding supports what was reported by many of the previous studies [6]' [21-24]. For double rooted MSM, only (type 0 ) and (type 1 ) occurred equally in buccal and palatal roots

In the present study, it was also noticed that (type 0), where root apices is locating away from MSF, increase in occurrence with increasing age as seen in tables 4 and 5, indicating a decrease in sinus size in older age groups with statistically significant difference ( $P$-value $<0.001)$ between the three age groups for all roots of $\mathrm{MM}$, while MP roots revealed nonsignificant difference which could be related to the fact that most of roots 
of MP already had a (type 0 ) relationship with MS and other types occur in small ratios. This finding is supporting what was reported by Tang et al. [23], in their study on Chinese population. Also, Similar finding was reported by other researchers [6]' [19]' [25].

The longest VLM mean in MP was reported for single rooted MFP $(8.39 \pm 2.80 \mathrm{~mm})$ and $(7.50 \pm 3.51 \mathrm{~mm})$ on both sides respectively, followed by BR of double rooted MFP, shorter distance was seen in PR but the shortest distance in MP was measured between PR of MSP and MSF $(2.11 \pm 5.00 \mathrm{~mm})$ for right and $(1.67 \pm 2.06 \mathrm{~mm})$ for left side (table 6$)$, these measurements go in line with what was reported by many preceding studies [6]' [14]' [19-20]'[26].

VLM in case of MM are much less than what was reported for premolars, as mentioned above; the shortest distance was found between MBR of MSM and MSF $(-0.30 \pm 2.451 \mathrm{~mm})$ on the right and $(-0.09 \pm 2.332 \mathrm{~mm})$ on the left side, followed by DBR of the MSM that have a distance of $(0.57 \pm 2.566 \mathrm{~mm})$ and $(0.59 \pm 2.663 \mathrm{~mm})$ on the right and left sides respectively. Such finding is also stated by many previous studies [4]' [20]' [27], other researchers reported that DBR of MSM has the shortest mean distance to MSF [28-29], racial differences and using panoramic radiography instead of CBCT could be related to these different readings.

According to the measurements recorded in the present study, it looks logical to state that Type 0 , when root apex was below the MSF, is relatively safe to perform dental procedure as nonsurgical endodontic treatment with low risk of spread of periapical infection into MS, although surgical procedures should be carefully performed particularly in MM. Other types (I, II and III), which are either in contact with or protrude inside MS, had more probability to induce odontogenic originated sinus infections with obvious risk of MSF perforation during periapical surgery indicating professional analysis of CBCT images prior to any surgical procedure in this anatomical region. Such conclusion was also emphasized by Tang et al. [17]

The results of the present study could help to conduct a research base for relation of maxillary posterior teeth to the MS with VLM between roots and MSF in southern Iraqi population that might be of clinical value for dentistry practitioners and dental surgeons.

\section{Conclusions}

Most of MP roots was seen to be separated from MS (type 0). The same finding but in less ratio was reported for MFM. Most of the MBR and DBR of MSM were in contact with the sinus floor (type1), while most of PR was separated from MS (type 0). The shortest VLM were reported in MBR of MSM.

6. Patents

None

\section{Declarations}

-Ethics approval and consent to participate: 
This study was approved by Ethical Review Committee at College of Dentistry, university of Basrah. All methods were carried out in accordance with relevant guidelines and regulations. Informed consent was obtained from all participants

-Consent for publication

Publisher has the permission of the Author to publish this work.

-Availability of data and materials

All data related to this work could be obtained by asking the corresponding author (aqeel.lazim@uobasrah.edu.iq)

-Competing interests:

The authors declare no conflicts of interest.

-Funding:

This research received no external funding

-Authors' contributions:

"Conceptualization, Aqeel Ibrahim Lazim Al-Saedi. and Riad AL-Taee; methodology, Aqeel Ibrahim Lazim AlSaedi; software Aqeel Ibrahim Lazim Al-Saedi; validation, Aqeel Ibrahim Lazim Al-Saedi, Riad AL-Taee and Bahaa AL-Bakhakh; formal analysis, Aqeel Ibrahim Lazim Al-Saedi; investigation, Saedi, Riad AL-Taee and Bahaa AL-Bakhakh.; resources, Aqeel Ibrahim Lazim Al-Saedi; data curation, Aqeel Ibrahim Lazim Al-Saedi; writing-original draft preparation, Aqeel Ibrahim Lazim Al-Saedi; writing-review and editing, Riad AL-Taee; visualization, Aqeel Ibrahim Lazim Al-Saedi, Riad AL-Taee and Bahaa AL-Bakhakh; supervision Aqeel Ibrahim Lazim Al-Saedi; project administration, Aqeel Ibrahim Lazim Al-Saedi; funding acquisition, none All authors have read and agreed to the published version of the manuscript.", .

-Acknowledgements:

None

\section{References}

1. Souza A, Rajagopal K, Ankolekar V, Souza AS, Kotian S. Anatomy of maxillary sinus and its ostium: A radiological study using computed tomography. CHRISMED J Heal Res. 2016;3(1):37. doi:10.4103/23483334.172397

2. Hauman $\mathrm{CHJ}$, Chandler NP, Tong DC. Endodontic implications of the maxillary sinus: A review. Int Endod J. 2002;35(2):127-141. doi:10.1046/j.0143-2885.2001.00524.x

3. Mattar E, Hammad L, Faden A, Khalil H. Relation of maxillary teeth to the maxillary sinus in normal Saudi individuals living in Riyadh. Biosci Biotechnol Res Asia. 2010;7(2):695-700. 
4. Eberhardt JA, Torabinejad M, Christiansen EL. A computed tomographic study of the distances between the maxillary sinus floor and the apices of the maxillary posterior teeth. Oral Surgery, Oral Med Oral Pathol. 1992;73(3):345-347. doi:10.1016/0030-4220(92)90133-B

5. Estrela C, Nunes CABCM, Guedes OA, et al. Study of anatomical relationship between posterior teeth and maxillary sinus floor in a subpopulation of the Brazilian central region using cone-beam computed tomography - Part 2. Braz Dent J. 2016;27(1):9-15. doi:10.1590/0103-6440201600679

6. Gu Y, Sun C, Wu D, Zhu Q, Leng D, Zhou Y. Evaluation of the relationship between maxillary posterior teeth and the maxillary sinus floor using cone-beam computed tomography. BMC Oral Health. 2018;18(1):1-7. doi:10.1186/s12903-018-0626-z

7. Kirkham-Ali K, La M, Sher J, Sholapurkar A. Comparison of cone-beam computed tomography and panoramic imaging in assessing the relationship between posterior maxillary tooth roots and the maxillary sinus: A systematic review. J Investig Clin Dent. 2019;10(3):e12402. doi:10.1111/jicd.12402

8. Hussein ZA, Al-Nakib LH. Assessment of the Relationship between Maxillary Sinus Floor and Maxillary Posterior Teeth Root Apices Using Spiral CT Scan. J Baghdad Coll Dent. 2017;25(3):80-86. doi:10.12816/0015001

9. Nunes CABCM, Guedes OA, Alencar AHG, Peters OA, Estrela CRA, Estrela C. Evaluation of Periapical Lesions and Their Association with Maxillary Sinus Abnormalities on Cone-beam Computed Tomographic Images. J Endod. 2016;42(1). doi:10.1016/j.joen.2015.09.014

10. Enas Anter* YH and WS. THE MAXILLARY SINUS FLOOR IN A SAMPLE FROM THE EGYPTIAN. 2019;65:3427-3438.

11. Shakhawan, M., Falah, A., Kawa A. The Relation of Maxillary Posterior Teeth Roots to the Maxillary Sinus Floor Using Panoramic and Computed Tomography Imaging in a Sample of Kurdish People Key words. Tikrit J Dent Sci. 2012;1:81-88.

12. Evaluation of Maxillary Molars Roots Relation to Maxillary Sinus Floor by using Cone Beam Computed Tomography. IAl-Kurwi, Hiba Abdul Azez; Areej Najm; Noor Allawi; Abbasnternational J Sci Res. 2018;7(10):784-786. doi:10.21275/ART20191877

13. Jung $\mathrm{Y}-\mathrm{H}$, Cho $\mathrm{B}-\mathrm{H}$. Comparison of panoramic radiography and cone beam computed tomography for assessing the relationship between the maxillary sinus floor and maxillary molars. Imaging Sci Dent. 2009;39(2):69-73.

\section{Tables}

Table 1: Frequency of type of relationship between roots apices of maxillary premolars and maxillary sinus floor 


\begin{tabular}{|c|c|c|c|c|c|}
\hline Root & Tooth & Type 0 & Type 1 & Type 2 & Type 3 \\
\hline \multirow{6}{*}{ single } & 14 & $56(100 \%)$ & $0(0 \%)$ & $0(0 \%)$ & $0(0 \%)$ \\
\hline & 24 & 48 (96\%) & $2(4 \%)$ & $0(0 \%)$ & $0(0 \%)$ \\
\hline & Total & $104(98.1 \%)$ & $2(1.9 \%)$ & $0(100 \%)$ & $0(0 \%)$ \\
\hline & 15 & $74(68.5 \%)$ & $34(31.5 \%)$ & $0(0 \%)$ & $0(0 \%)$ \\
\hline & 25 & $76(70.4 \%)$ & $26(24 \%)$ & $4(3.7 \%)$ & $2(1.9 \%)$ \\
\hline & Total & $150(69.5 \%)$ & $60(27.8 \%)$ & $4(1.8 \%)$ & $2(0.9 \%)$ \\
\hline \multirow{6}{*}{ Buccal } & 14 & $70(100 \%)$ & $0(0 \%)$ & $0(0 \%)$ & $0(0 \%)$ \\
\hline & 24 & 78 (97.5\%) & $2(2.5 \%)$ & $0(0 \%)$ & $0(0 \%)$ \\
\hline & Total & 148(98.7\%) & $2(1.3 \%)$ & $(0 \%)$ & $0(0 \%)$ \\
\hline & 15 & 8 (36.4\%) & $12(54.5 \%)$ & $2(9.1 \%)$ & $0(0 \%)$ \\
\hline & 25 & $16(61.5 \%)$ & $10(38.5 \%)$ & $0(0 \%)$ & $0(0 \%)$ \\
\hline & Total & $24(50 \%)$ & $22(45.8 \%)$ & $2(4.2 \%)$ & $0(0 \%)$ \\
\hline \multirow{6}{*}{ Palatal } & 14 & $62(88.6 \%)$ & $8(11.4 \%)$ & $0(0 \%)$ & $0(0 \%)$ \\
\hline & 24 & 76 (95\%) & $4(5 \%)$ & $0(0 \%)$ & $0(0 \%)$ \\
\hline & Total & 138(92\%) & $12(8 \%)$ & $0(0 \%)$ & $0(0 \%)$ \\
\hline & 15 & 8 (36.4\%) & 8 (36.4\%) & $0(0 \%)$ & $6(27.2 \%)$ \\
\hline & 25 & $14(53.8 \%)$ & $12(46.2 \%)$ & $0(0 \%)$ & $0(0 \%)$ \\
\hline & Total & $22(45.8 \%)$ & $20(41.7 \%)$ & $0(0 \%)$ & $6(12.5 \%)$ \\
\hline
\end{tabular}

Table 2: Frequency of type of relationship between roots apices of single and multirooted maxillary molars and maxillary sinus floor 


\begin{tabular}{|c|c|c|c|c|c|}
\hline Root & Tooth & Type 0 & Type 1 & Type 2 & Type 3 \\
\hline \multirow{3}{*}{ Single } & 17 & $2(50 \%)$ & $2(50 \%)$ & $0(0 \%)$ & $0(0 \%)$ \\
\hline & 27 & $2(50 \%)$ & $2(50 \%)$ & $0(0 \%)$ & $0(0 \%)$ \\
\hline & Total & $4(50 \%)$ & $4(50 \%)$ & $0(0 \%)$ & $0(0 \%)$ \\
\hline \multirow{6}{*}{ mesiobuccal } & 16 & $58(42.6 \%)$ & $24(22 \%)$ & $38(28 \%)$ & $10(7.4 \%)$ \\
\hline & 26 & 52 (41.9\%) & $22(17.7 \%)$ & 42 (33.9\%) & 8 (6.5\%) \\
\hline & Total & $110(43.3 \%)$ & $46(18.1 \%)$ & $80(31.5 \%)$ & 18(7.1\%) \\
\hline & 17 & $22(16.2 \%)$ & $64(47.1 \%)$ & $6(4.4 \%)$ & 44 (32.3\%) \\
\hline & 27 & $20(15.6 \%)$ & $56(43.7 \%)$ & $18(14.1 \%)$ & 34 (26.6\%) \\
\hline & Total & $42(15.9 \%)$ & $120(45.5 \%)$ & $24(9 \%)$ & $78(29.6 \%)$ \\
\hline \multirow{6}{*}{ Distobuccal } & 16 & $53(40.8)$ & 25 (19.2\%) & $39(30 \%)$ & $13(10 \%)$ \\
\hline & 26 & $51(41.1 \%)$ & 27 (21.8\%) & 37 (29.8\%) & $9(7.3 \%)$ \\
\hline & Total & 104(39.8\%) & $52(20.4 \%)$ & $76(30.8 \%)$ & $22(9 \%)$ \\
\hline & 17 & $30(23.1 \%)$ & $60(46.1 \%)$ & $16(12.3 \%)$ & 24 (18.5\%) \\
\hline & 27 & 32 (25.8\%) & $62(50 \%)$ & 10 (8.1\%) & $20(16.1 \%)$ \\
\hline & Total & $62(24.4 \%)$ & $122(48.1 \%)$ & $26(10.2 \%)$ & $44(17.3 \%)$ \\
\hline \multirow{6}{*}{ Palatal } & 16 & 50 (38.5\%) & $15(11.5 \%)$ & $44(33.8 \%)$ & $21(16.2 \%)$ \\
\hline & 26 & 48 (38.7\%) & 25 (20.2\%) & $25(20.2 \%)$ & $26(20.9 \%)$ \\
\hline & Total & $98(38.6 \%)$ & $40(15.7 \%)$ & $69(27.2 \%)$ & $47(18.5 \%)$ \\
\hline & 17 & 48 (35.3\%) & $34(25 \%)$ & $44(32.4 \%)$ & $10(7.3 \%)$ \\
\hline & 27 & $52(40.6 \%)$ & 44 (34.4\%) & $24(18.8 \%)$ & $8(6.2 \%)$ \\
\hline & Total & $100(37.9 \%)$ & $78(29.5 \%)$ & $68(25.8 \%)$ & $18(6.8 \%)$ \\
\hline
\end{tabular}

Table 3: Frequency of type of relationship between roots apices of double rooted maxillary second molars and maxillary sinus floor. 


\begin{tabular}{|llllll|}
\hline Root & Tooth & Type 0 & Type 1 & Type2 & Type 3 \\
\hline Buccal & 17 & $2(50 \%)$ & $2(50 \%)$ & $0(0 \%)$ & $0(0 \%)$ \\
\cline { 2 - 6 } & 27 & $2(50 \%)$ & $2(50 \%)$ & $0(0 \%)$ & $0(0 \%)$ \\
\cline { 2 - 6 } palatal & Total & $4(50 \%)$ & $4(50 \%)$ & $0(0 \%)$ & $0(0 \%)$ \\
& 17 & $2(50 \%)$ & $2(50 \%)$ & $0(0 \%)$ & $0(0 \%)$ \\
& 27 & $2(50 \%)$ & $2(50 \%)$ & $0(0 \%)$ & $0(0 \%)$ \\
& & & & & \\
& Total & $4(50 \%)$ & $4(50 \%)$ & $0(0 \%)$ & $0(0 \%)$ \\
\hline
\end{tabular}

Table 4: Distribution of type of relationship between roots apices of maxillary premolars and maxillary sinus floor according to age 


\begin{tabular}{|c|c|c|c|c|c|c|c|c|}
\hline Root & Tooth & Age & Type 0 & Type 1 & Type 2 & Type 3 & Total & $\begin{array}{l}\text { P- } \\
\text { Value* }\end{array}$ \\
\hline \multirow{6}{*}{ Single } & \multirow{3}{*}{ First premolar } & $<30$ & $76(98.7 \%)$ & $1(1.3 \%)$ & $0(0 \%)$ & $0(0 \%)$ & 77 & \multirow[t]{3}{*}{0.529} \\
\hline & & $\begin{array}{l}30- \\
45\end{array}$ & $18(94.7 \%)$ & $1(5.6 \%)$ & $0(0 \%)$ & $0(0 \%)$ & 19 & \\
\hline & & $>45$ & $16(100 \%)$ & $0(0 \%)$ & $0(0 \%)$ & $0(0 \%)$ & 16 & \\
\hline & \multirow{3}{*}{$\begin{array}{l}\text { Second } \\
\text { premolar }\end{array}$} & $<30$ & $83(61.5 \%)$ & $47(34.8 \%)$ & $3(2.2 \%)$ & $2(1.5 \%)$ & 135 & \multirow[t]{3}{*}{0.110} \\
\hline & & $\begin{array}{l}30- \\
45\end{array}$ & $30(78.9 \%)$ & $7(18.5 \%)$ & $1(2.6 \%)$ & $0(0 \%)$ & 38 & \\
\hline & & $>45$ & $27(81.8 \%)$ & $6(18.2 \%)$ & $0(0 \%)$ & $0(0 \%)$ & 33 & \\
\hline \multirow[b]{6}{*}{ Buccal } & \multirow{3}{*}{ First premolar } & $<30$ & $79(97.5 \%)$ & $2(2.5 \%)$ & $0(0 \%)$ & $0(0 \%)$ & 81 & \multirow[t]{3}{*}{0.702} \\
\hline & & $\begin{array}{l}30- \\
45\end{array}$ & $41(100 \%)$ & $0(0 \%)$ & $0(0 \%)$ & $0(0 \%)$ & 41 & \\
\hline & & $>45$ & $28(100 \%)$ & $0(0 \%)$ & $0(0 \%)$ & $0(0 \%)$ & 28 & \\
\hline & \multirow{3}{*}{$\begin{array}{l}\text { Second } \\
\text { premolar }\end{array}$} & $<30$ & $16(47 \%)$ & $16(47 \%)$ & $2(6 \%)$ & $0(0 \%)$ & 34 & \multirow[t]{3}{*}{0.522} \\
\hline & & $\begin{array}{l}30- \\
45\end{array}$ & $8(57.1 \%)$ & $6(42.9 \%)$ & $0(0 \%)$ & $0(0 \%)$ & 14 & \\
\hline & & $>45$ & $2(100 \%)$ & $0(0 \%)$ & $0(0 \%)$ & $0(0 \%)$ & 2 & \\
\hline \multirow{6}{*}{ Palatal } & \multirow{3}{*}{ First premolar } & $<30$ & $75(92.6 \%)$ & $6(7.4 \%)$ & $0(0 \%)$ & $0(0 \%)$ & 81 & \multirow[t]{3}{*}{0.088} \\
\hline & & $\begin{array}{l}30- \\
45\end{array}$ & $35(85.4 \%)$ & $6(14.6)$ & $0(0 \%)$ & $0(0 \%)$ & 41 & \\
\hline & & $>45$ & $28(100 \%)$ & $0(0 \%)$ & $0(0 \%)$ & $0(0 \%)$ & 28 & \\
\hline & \multirow{3}{*}{$\begin{array}{l}\text { Second } \\
\text { premolar }\end{array}$} & $<30$ & $14(41.2 \%)$ & $16(47.1 \%)$ & $0(0 \%)$ & $4(11.7 \%)$ & 34 & \multirow[t]{3}{*}{0.345} \\
\hline & & $\begin{array}{l}30- \\
45\end{array}$ & $8(57.1 \%)$ & $4(28.6 \%)$ & $0(0 \%)$ & $2(14.3 \%)$ & 14 & \\
\hline & & $>45$ & $2(100 \%)$ & $0(0 \%)$ & $0(0 \%)$ & $0(0 \%)$ & 2 & \\
\hline
\end{tabular}

${ }^{*}$ Chi-squared $t$ test

Table 5: Distribution of type of relationship between roots apices of single and multirooted maxillary molars and maxillary sinus floor according to age. 


\begin{tabular}{|c|c|c|c|c|c|c|c|c|}
\hline Root & Tooth & Age & Type 0 & Type 1 & Type 2 & Type 3 & Total & $\begin{array}{l}\text { P- } \\
\text { Value* }\end{array}$ \\
\hline \multirow{3}{*}{ Single } & \multirow{3}{*}{$\begin{array}{l}\text { Second } \\
\text { molar }\end{array}$} & $<30$ & $2(3.33 \%)$ & $4(66.67 \%)$ & $0(0 \%)$ & $0(0 \%)$ & 6 & \multirow[t]{3}{*}{-} \\
\hline & & $\begin{array}{l}30- \\
45\end{array}$ & $2(100 \%)$ & $0(0 \%)$ & $0(0 \%)$ & $0(0 \%)$ & 2 & \\
\hline & & $>45$ & $0(0 \%)$ & $0(0 \%)$ & $0(0 \%)$ & $0(0 \%)$ & 0 & \\
\hline \multirow{6}{*}{ Mesiobuccal } & \multirow{3}{*}{$\begin{array}{l}\text { First } \\
\text { molar }\end{array}$} & $<30$ & $45(29.8 \%)$ & $31(20.5 \%)$ & $61(40.4 \%)$ & $14(9.3 \%)$ & 151 & \multirow[t]{3}{*}{$<0.001$} \\
\hline & & $\begin{array}{l}30- \\
45\end{array}$ & $36(60 \%)$ & 11(18.3\%) & $11(18.3 \%)$ & $2(3.4 \%)$ & 60 & \\
\hline & & $>45$ & $29(67.4 \%)$ & $4(9.3 \%)$ & $8(18.6 \%)$ & $2(4.7 \%)$ & 43 & \\
\hline & \multirow{3}{*}{$\begin{array}{l}\text { Second } \\
\text { molar }\end{array}$} & $<30$ & $15(9.4 \%)$ & $63(39.4 \%)$ & $16(10 \%)$ & $66(41.2 \%)$ & 160 & \multirow[t]{3}{*}{$<0.001$} \\
\hline & & $\begin{array}{l}30- \\
45\end{array}$ & $16(24.2 \%)$ & $38(57.5 \%)$ & $4(6.1 \%)$ & $8(12.2 \%)$ & 66 & \\
\hline & & $>45$ & $11(29 \%)$ & $19(50 \%)$ & $4(10.5 \%)$ & $4(10.5 \%)$ & 38 & \\
\hline \multirow{6}{*}{ Distobuccal } & \multirow{3}{*}{$\begin{array}{l}\text { First } \\
\text { molar }\end{array}$} & $<30$ & $37(24.5 \%)$ & $37(24.5 \%)$ & $55(36.4 \%)$ & $22(14.6 \%)$ & 151 & \multirow[t]{3}{*}{$<0.001$} \\
\hline & & $\begin{array}{l}30- \\
45\end{array}$ & $36(60 \%)$ & 11(18.3\%) & $13(21.7 \%)$ & $0(0 \%)$ & 60 & \\
\hline & & $>45$ & $31(72.1 \%)$ & $4(9.3 \%)$ & $8(18.6 \%)$ & $0(0 \%)$ & 43 & \\
\hline & \multirow{3}{*}{$\begin{array}{l}\text { Second } \\
\text { molar }\end{array}$} & $<30$ & $27(16.9 \%)$ & $77(48.1 \%)$ & $24(15 \%)$ & $32(20 \%)$ & 160 & \multirow[t]{3}{*}{$<0.001$} \\
\hline & & $\begin{array}{l}30- \\
45\end{array}$ & $18(27.3 \%)$ & $42(63.77 \%)$ & $1(1.5 \%)$ & $5(7.5 \%)$ & 66 & \\
\hline & & $>45$ & $21(55.3 \%)$ & $13(34.2 \%)$ & $4(10.5 \%)$ & $0(0 \%)$ & 38 & \\
\hline \multirow{6}{*}{ Palatal } & \multirow{3}{*}{$\begin{array}{l}\text { First } \\
\text { molar }\end{array}$} & $<30$ & $39(25.8 \%)$ & $21(13.9 \%)$ & $52(34.5 \%)$ & $39(25.8 \%)$ & 151 & \multirow[t]{3}{*}{$<0.001$} \\
\hline & & $\begin{array}{l}30- \\
45\end{array}$ & $34(56.6 \%)$ & $12(20 \%)$ & $7(11.7 \%)$ & $7(11.7 \%)$ & 60 & \\
\hline & & $>45$ & $27(62.8 \%)$ & $4(9.3 \%)$ & $10(23.3 \%)$ & $2(4.6 \%)$ & 43 & \\
\hline & \multirow{3}{*}{$\begin{array}{l}\text { Second } \\
\text { molar }\end{array}$} & $<30$ & $51(31.9 \%)$ & $39(24.4 \%)$ & $56(35 \%)$ & $14(8.7 \%)$ & 160 & \multirow[t]{3}{*}{$<0.001$} \\
\hline & & $\begin{array}{l}30- \\
45\end{array}$ & $26(39.4 \%)$ & $34(51.5 \%)$ & $4(6.1 \%)$ & $2(3 \%)$ & 66 & \\
\hline & & $>45$ & $23(60.5 \%)$ & $5(13.1 \%)$ & $8(21.1 \%)$ & $2(5.3 \%)$ & 38 & \\
\hline
\end{tabular}

${ }^{*}$ Chi-squared t test

Table 6: Linear measurements between apices of maxillary premolars and floor of maxillary sinus. 


\begin{tabular}{|c|c|c|c|c|c|c|}
\hline Root & Tooth & No. & Mean & S.D. & Min. & Max. \\
\hline \multirow{4}{*}{ single } & 14 & 62 & 8.39 & 2.80 & 1.70 & 13.43 \\
\hline & 24 & 50 & 7.50 & 3.51 & 0.00 & 12.83 \\
\hline & 15 & 108 & 3.17 & 2.86 & 0.00 & 8.6 \\
\hline & 25 & 108 & 3.71 & 3.45 & -2.94 & 11.11 \\
\hline \multirow{4}{*}{ Buccal } & 14 & 70 & 8.24 & 3.76 & 0.60 & 15.97 \\
\hline & 24 & 80 & 7.49 & 3.37 & 0.00 & 14.68 \\
\hline & 15 & 22 & 3.13 & 4.59 & 0.00 & 12.77 \\
\hline & 25 & 28 & 2.04 & 2.1 & 0.00 & 6.18 \\
\hline \multirow{4}{*}{ Palatal } & 14 & 70 & 6.84 & 4.66 & 0.00 & 16.66 \\
\hline & 24 & 80 & 7.02 & 4.16 & 0.00 & 18.96 \\
\hline & 15 & 22 & 2.11 & 5.00 & -3.65 & 12.19 \\
\hline & 25 & 28 & 1.67 & 2.06 & 0.00 & 6.47 \\
\hline
\end{tabular}

Table 7: Linear measurements between apices of single and multi-rooted maxillary molars and floor of maxillary sinus 


\begin{tabular}{|lllllll|}
\hline Root & Tooth & No. & Mean & SD & Min. & Max. \\
\hline Single & 17 & 4 & 0.90 & 1.045 & 0 & 1.81 \\
\cline { 2 - 7 } & 27 & 4 & 0.9 & 1.125 & 0 & 1.95 \\
\hline mesiobuccal & 16 & 136 & 1.64 & 2.866 & -6.10 & 11.6 \\
& 26 & 130 & 1.55 & 2.885 & -2.96 & 11.52 \\
& 17 & 123 & -0.30 & 2.451 & -5.89 & 7.48 \\
\hline Distobuccal & 27 & 124 & -0.09 & 2.332 & -4.71 & 7.67 \\
& 17 & 132 & 0.57 & 2.566 & -3.94 & 9.20 \\
& 27 & 124 & 0.59 & 2.663 & -5.04 & 10.99 \\
& 16 & 136 & 1.42 & 2.874 & -4.30 & 13.1 \\
\hline \multirow{3}{*}{ Palatal } & 16 & 136 & 1.00 & 2.883 & -6.90 & 9.11 \\
& 26 & 130 & 1.09 & 3.336 & -4.91 & 8.99 \\
& 17 & 132 & 1.41 & 2.965 & -3.51 & 10.56 \\
& 27 & 128 & 1.68 & 3.175 & -5.05 & 15.73 \\
\hline
\end{tabular}

Table8: Vertical linear measurements between apices of double rooted maxillary second molars and floor of maxillary sinus

\begin{tabular}{|cllllll|}
\hline Root & Tooth & No. & Mean & SD & Min. & Max. \\
\hline Buccal & 17 & 4 & 0 & 0 & 0 & 0 \\
\cline { 2 - 7 } & 27 & 4 & 0 & 0 & 0 & 0 \\
\hline palatal & 17 & 4 & 1.13 & 1.304 & 0 & 2.26 \\
& 27 & 4 & 0.355 & 0.409 & 0 & 0.71 \\
\hline
\end{tabular}

\section{Figures}




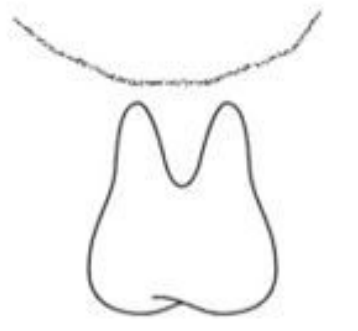

Type 0

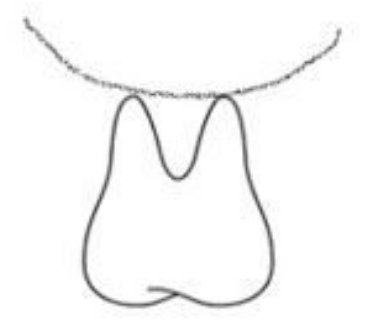

Type 1

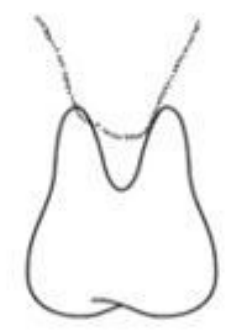

Type 2

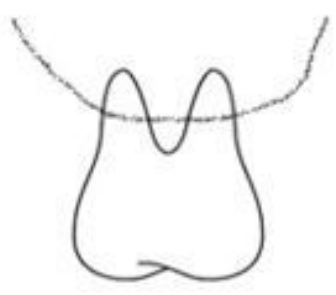

Type 3

\section{Figure 1}

classification of vertical relationship of maxillary sinus floor and maxillary posterior teeth13 Type 0: In which the root is separated from (below) inferior wall of MS (fig.2 a). Type 1: In which the root is in contact inferior wall of MS (fig. 2 b). Type 2: In which the root is projected laterally (tangential) to the inferior wall of MS without protrusion into the sinus (fig. 2 c). Type 3 : In which the root is protruded into the inferior wall of MS (fig 2 d). 


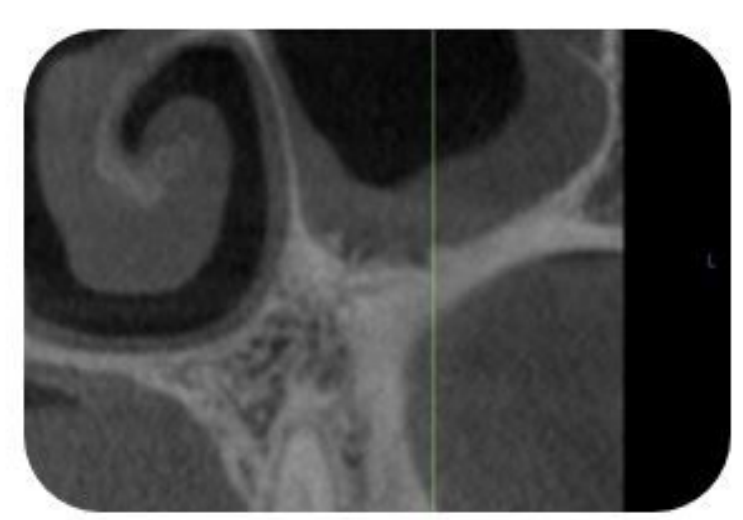

Figure $2 a$

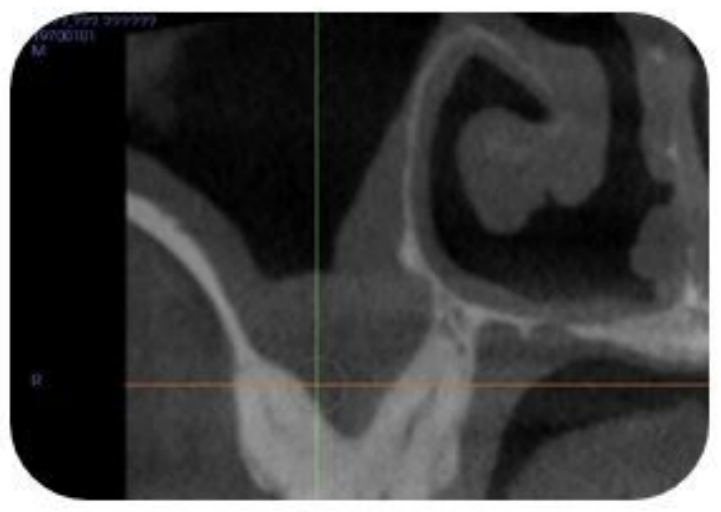

Figure $2 c$

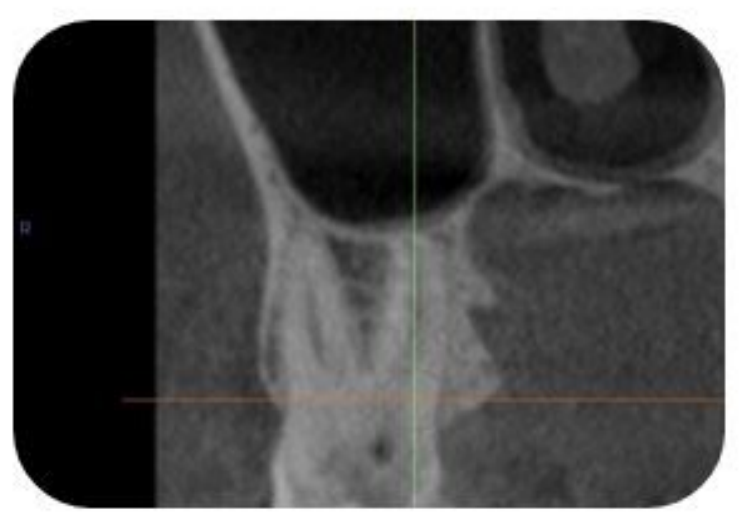

Figure $2 b$

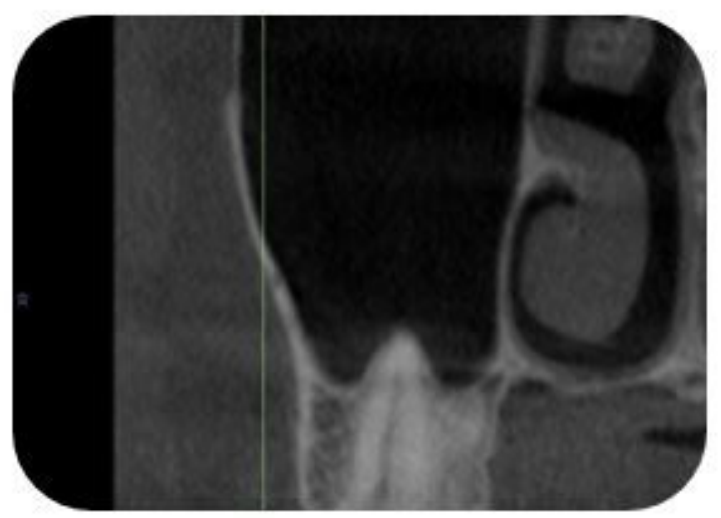

Figure $2 d$

\section{Figure 2}

Types of relationship between roots of maxillary posterior teeth and inferior wall of maxillary sinus as appeared in coronal section of CBCT Figure2a-type 0 Figure2 b-type 1 Figure2 c-type 2 Figure2 d-type 3 


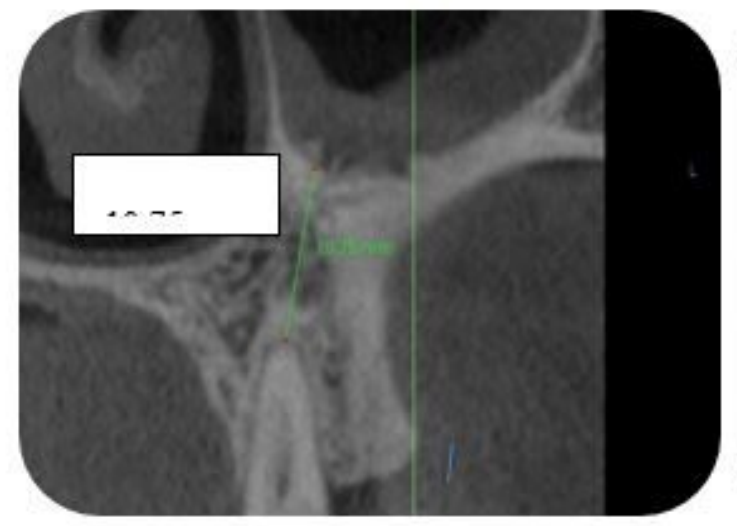

Figure $3 a$

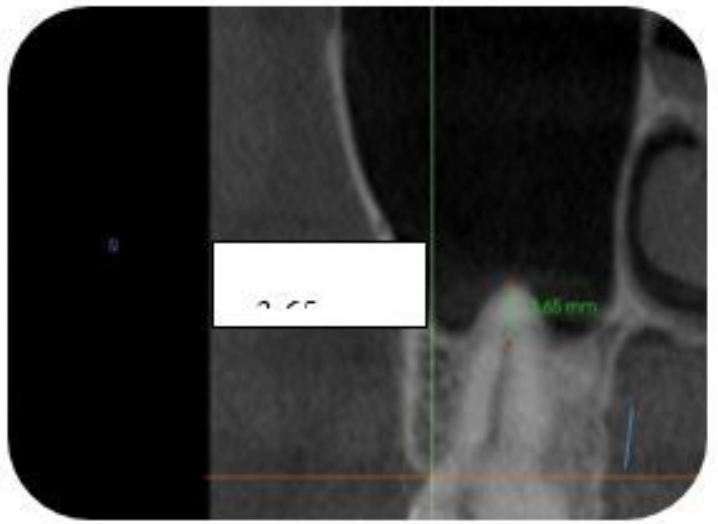

Figure $3 b$

\section{Figure 3}

Vertical linear measurement between roots of maxillary posterior teeth and inferior wall of maxillary sinus as appeared in coronal section of CBCT Figure 3 a: positive linear measurement Figure 3 b: negative linear measurement

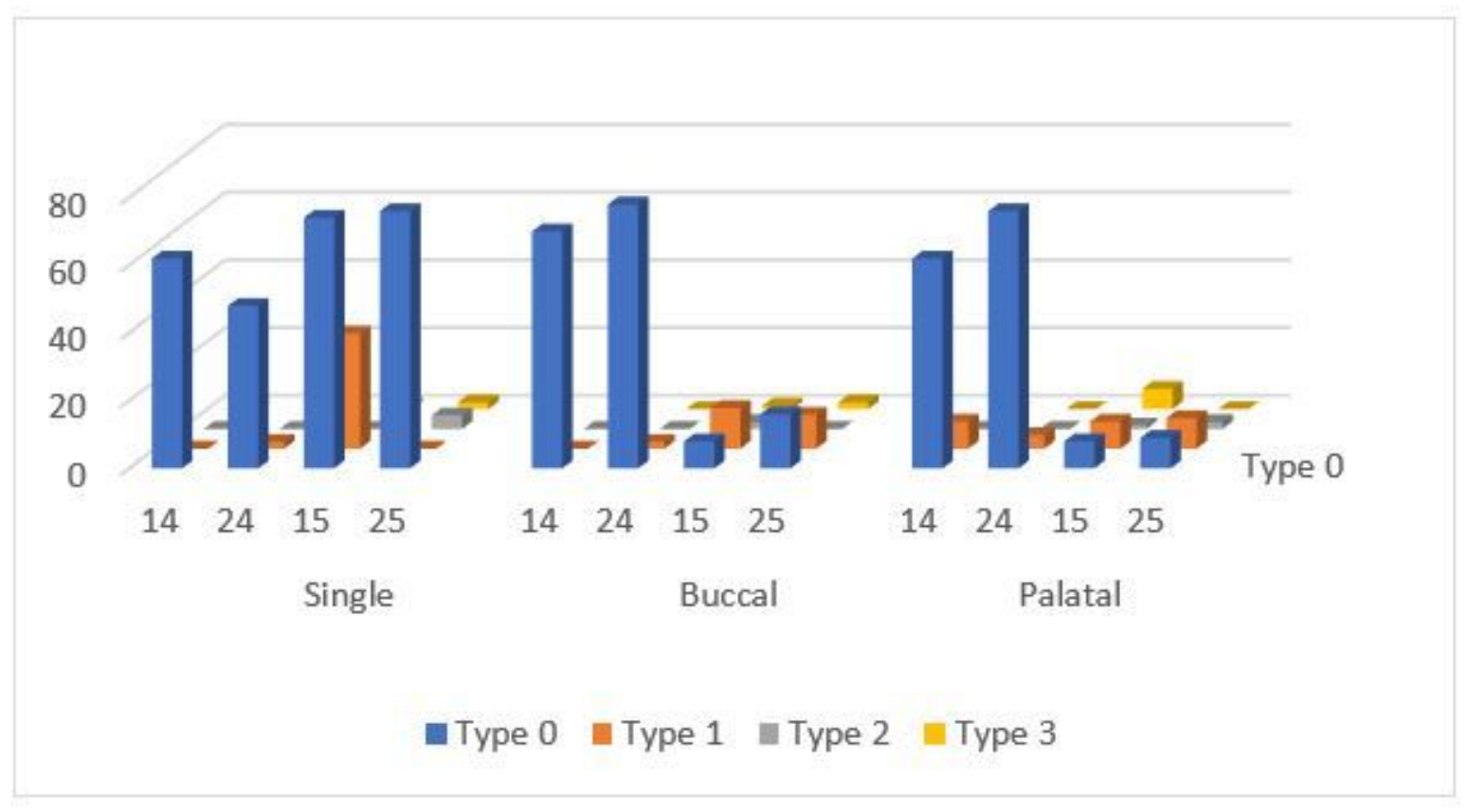

\section{Figure 4}

Frequency of type of relationship between roots apices of maxillary premolars and maxillary sinus floor 


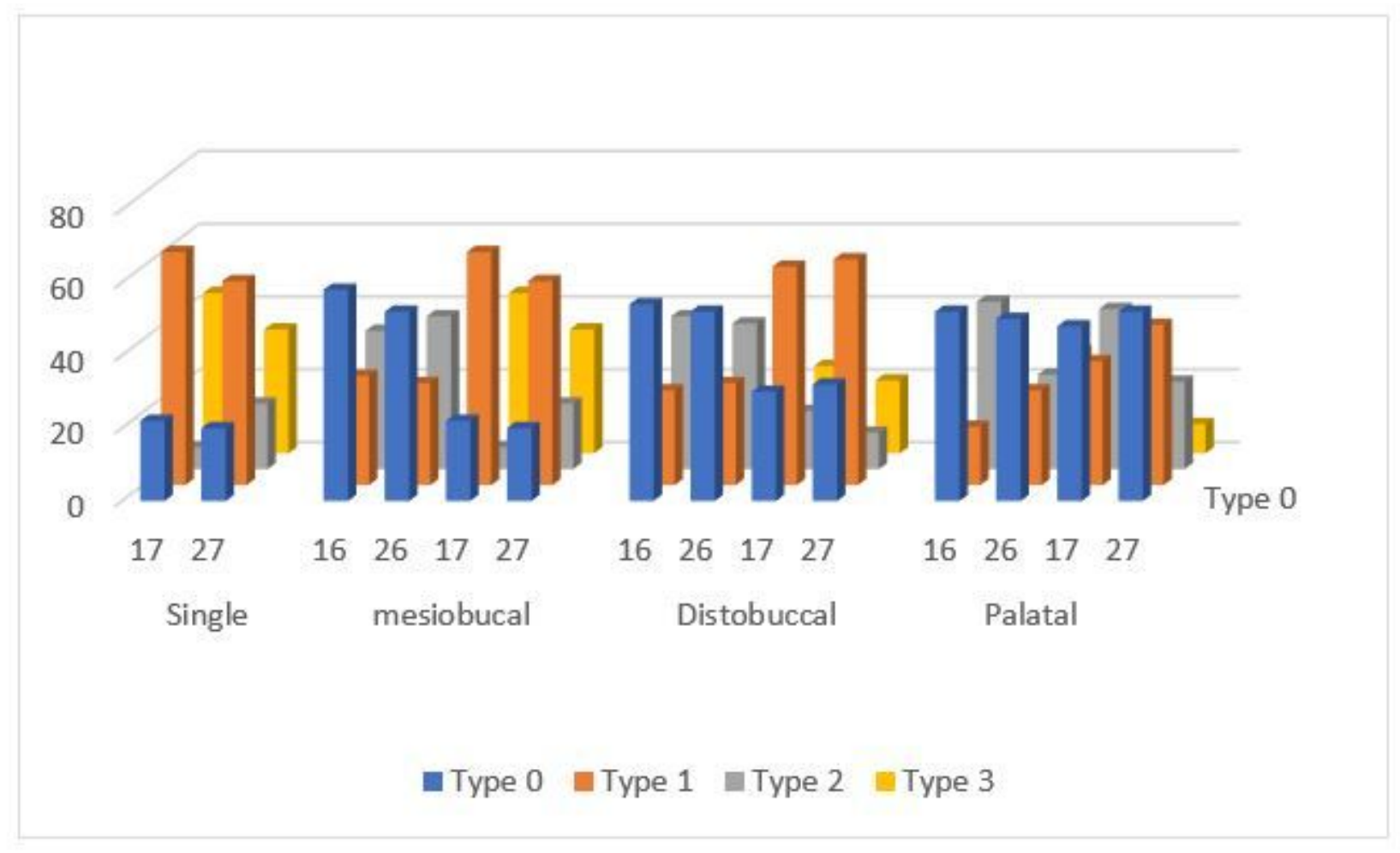

\section{Figure 5}

Frequency of type of relationship between roots apices of single and multirooted maxillary molars and maxillary sinus floor 